\title{
Consideration and Suggestion on College Audit Teaching
}

\author{
Li Pei ${ }^{1}$ \\ ${ }^{1}$ School of Economics andManagement, North China Electric Power University, Beijing 102206,
}

Keywords. audit; audit curriculum; reform

\begin{abstract}
College audit curriculum teaching was researched in accordance with the current national demand for auditing talents and the development situation of audit profession; then, corresponding solutions were put forward after a series of existing problems were analyzed.
\end{abstract}

\section{Background}

Audit has played a more and more important role in people's social and economic life since the reform and opening-up was activated over thirty years ago. A recent research report shows that as cash flow management becomes a market focus at present, many companies have increased demand for financial and auditing talents. The domestic accounting and banking employment market has also shown an active state and a special demand for auditing talents. Data suggests that from January to October of 2010, Chinese auditing agencies avoided and recouped losses of 11.89 billion yuan, helped the masses receive a compensation of 2.35 billion yuan, found out defective fiscal revenue and expenditure of 125.48 billion yuan, and directly increased revenue and reduced expenditure of 38.3 billion yuan for the state. But the case of Guangdong-Hainan Railway that occurred a few years ago and the scandal of Parmalat that happened in 2015 gave a wake-up call to us about the current auditing environment and auditing talent selection.

At the present stage, auditing talents should not only master modern audit methods and means, but also have very high professional ethics and qualities. As future auditing talents, we can't help pondering such aquestion: How can Chinese universities enable the auditing talents trained by them to better serve the society, help audit win trust from the public in the professional field, and make audit render a better service to the national economic construction? The following analysis is carried out based on this question.

\section{The Present Situation and Problems of College Audit Teaching (a case study of Beijing colleges)}

Audit textbooks have a quite high timeliness. At present, Chinese business accounting standards, public institution accounting standards and CPA's practices standards are all new versions promulgated or revised recently, whose contents are much different from the old ones. Moreover, new contents are added almost every year, so in order that the teaching objectives should be achieved and the social needs for auditing talents should be met, auditing textbooks need to be revised constantly.

The questionnaire data collected and sorted out by us suggests that CPA auditing textbook is adopted in $80.77 \%$ of the colleges, but the content of this textbook is obscure and made up of many silly rules and regulations, which overemphasizes the memory of technology education and associated regulations while neglecting the cultivation of quality-oriented education and ability, so it is not necessarily an appropriate auditing textbook for undergraduates. 
What is your school textbooks used in the auditing?

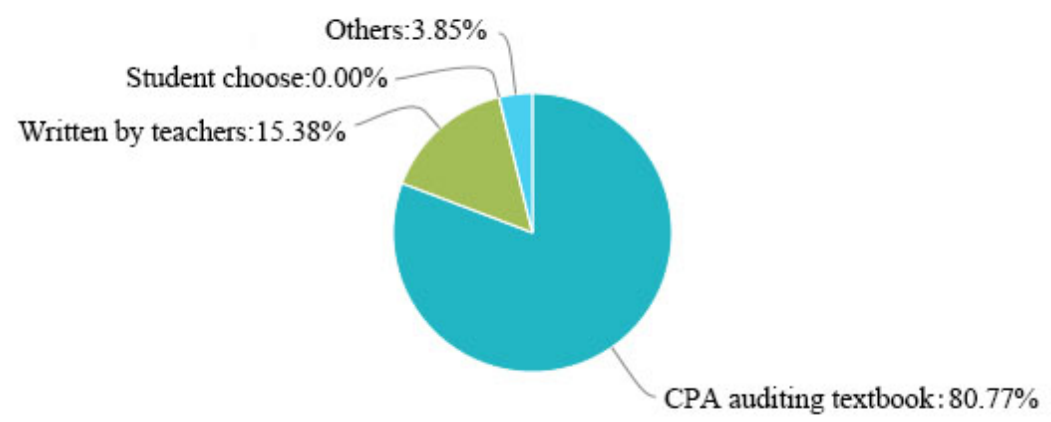

Audit is a discipline with extremely high applicability, characterized by high professionalization. General oral teaching can’t help students advance knowledge perceptually. The figure below illustrates a result of auditing cases in our questionnaire.

Problems in Case Teaching of Auditing

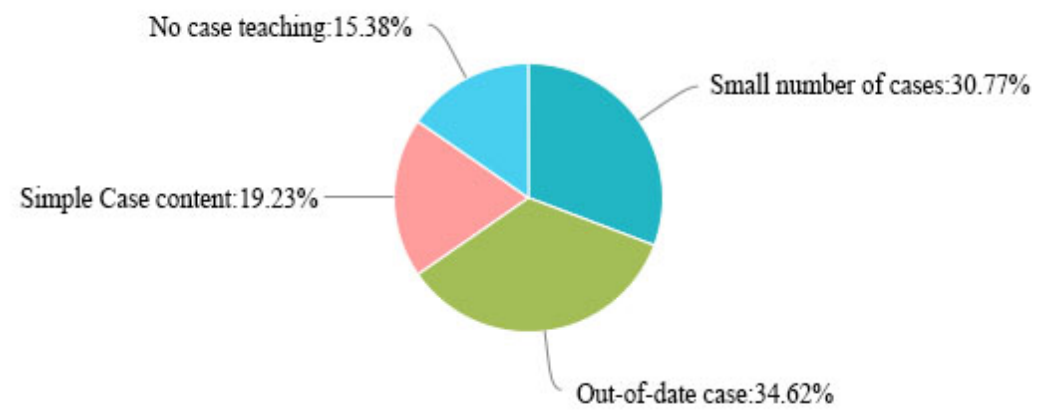

Thus we discover that case teaching should even more be carried out to make students understand auditing practices. This will not only help exercise students’ practical work ability, but help deepen their understanding of audit theory. However, there is hardly any specialized "case analysis" course in the present auditing teacher or the cases are not complete and systematic, but too outdated.

Audit isn't a subject that can be learned well "only in classroom"; on the contrary, it is a discipline with extremely high applicability, characterized by high professionalization. To learn audit well, students should not only master the theoretical knowledge, but also practice while learning, since practice is also very important. But at present, college audit teaching is primarily based on theory, and there is also the lack of an auditing practice teaching base. 


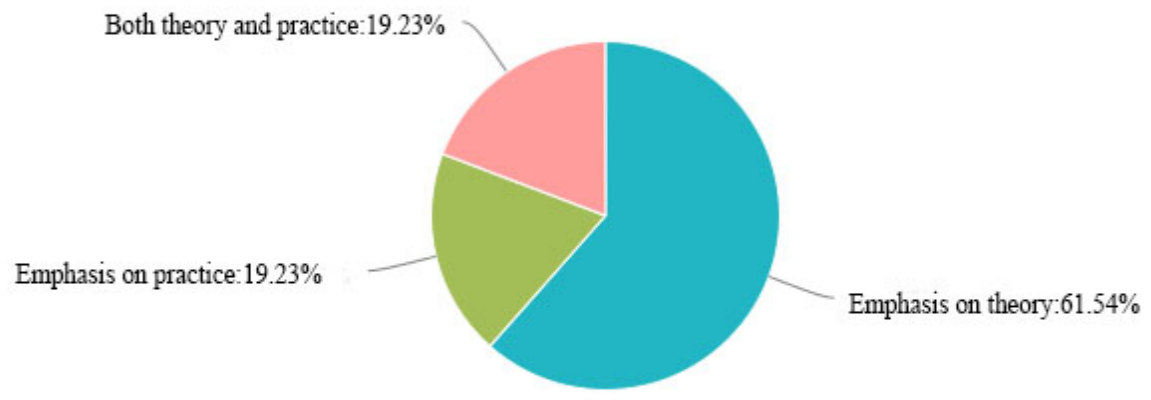

Nowadays, curriculum assessment generally falls into two parts: one is daily performance, including classroom performance, assignment and attendance; the other is final test score, which serves as a major part of curriculum assessment result in most colleges. This way of assessment overemphasizes the degree of students' mastery of knowledge, but ignores students' attitude towards learning, team spirit and application ability. As is indicated by the result of our questionnaire survey, $46.35 \%$ of the undergraduates holds a view that the present assessment result cannot reflect the real agree of their mastery of the audit course.

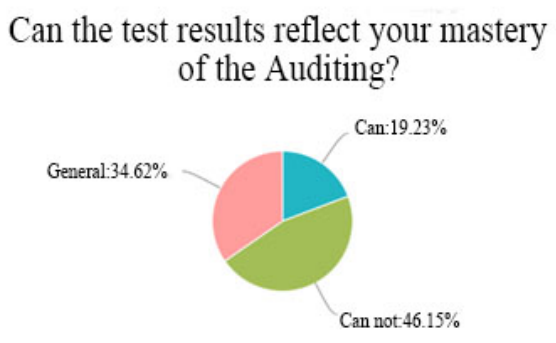

\section{Multi-dimensional Audit Curriculum Reform}

At present most of the colleges use an inappropriate textbook_—CPA Textbook. However, their audit teaching and research section and related teaching staff, including professors, should compile a suitable supplementary audit teaching material for CAP textbook in accordance with their many years of teaching experience according to the relevant teaching plan and objective. Apart from renewing the textbook in time, they should also use the supplementary teaching material and cases in class.

For case teaching, questions can be asked in class; the complex theoretical questions in the textbook ought to be avoided, but the theories to be explained in class ought to be imported. Auditing cases can be analyzed to let students combine their knowledge with auditing practice organically, to develop their comprehensive analysis ability and professional judgment. Cases come from practice, but the corresponding theories derived are often isolated from each other. So, course teacher must make a summary at the final stage of each class to form an interrelated knowledge system based upon the theories derived, so that students should be able to further understand the knowledge firmly and apply what they've learned to practice.

It's suggested that a heuristic performance assessment standard should be set to change the old pattern that "a test paper decides the final achievement". A systematic, dynamic assessment standard needs to be set for the evaluation of students' achievements. The "two-two-six" performance assessment pattern implemented in some higher education institutions, such as North 
China Electric Power University, is worth using for reference. The performance assessed in this pattern consists of three parts: classroom discussion accounts for $20 \%$ of the total performance, simulated experiment or assignment accounts for $20 \%$ of the total performance, and final written test accounts for $60 \%$ of the total performance. In this way, the "unary" performance assessment standard can be gradually turned into a "pluralistic" performance assessment standard to ensure its matching with the heuristic research-oriented teaching pattern.

After-class practice can be carried out in a training base or auditing simulation laboratory. In particular, simulated experimental materials, including the background information, accounting data, audit working paper and audit report of an audit object, could be predesigned with corresponding experimental facilities. When an analogue experiment is conducted, students could be divided into several groups to play an auditor, an audit object or a client (or authorizer) in accordance with the auditing procedure stipulated in the auditing standards.

Besides, condition permitting, a senior auditor could be invited to give a special speech to deepen students' understanding of auditing practice to lay a solid foundation for their future work.

\section{References:}

[1]Zhang Xuemei. An Innovative Heuristic Research-oriented Audit Teaching Method

[2]Kan Jinghua. The Problems in Audit Curriculum Construction and Countermeasures

[3]Xu Xiangzhen, Chen Zhenfeng \& Wu Lanfei. Reform Measures forChinese College Audit Teaching Practice and Research

[4]Chen Jie \& Zeng Xiaohong. An Analysis on the Social Demand for Audit Talents in China

[5]Zhou Wen \& Li Xuelan. An Analysis on the Demand for Audit Talents in China

[6]Jiang Ye \& Li Zhaohua. Research on the Mode of Audit Teaching Innovation in the General International Environment

[7]Xin Xu. The Problems in Case-based Audit Teaching and Countermeasures

[8]Sun Weilong. Initial Discussion on the Reform of Auditing Teaching for College Accounting Profession 